\section{OP0112 IN INDIVIDUALS AT RISK OF INFLAMMATORY ARTHRITIS, PATIENT REPORTED OUTCOMES DETERIORATE IN THE 12 WEEKS BEFORE PROGRESSION TO CLINICAL DISEASE}

L. Duquenne ${ }^{1,2}$, K. Mankia $^{1,2}$, L. Garcia-Montoya ${ }^{1,2}$, J. Nam $^{1,2}$, A. Di Matteo ${ }^{1,2}$, P. Emery ${ }^{1,2} .{ }^{1}$ Leeds Institute of Rheumatic and Musculoskeletal Medicine, LEEDS, United Kingdom; ${ }^{2}$ Leeds Biomedical Research Centre - NIHR, LEEDS, United Kingdom

Background: Subjects with clinically significant arthralgia who will eventually develop inflammatory arthritis (IA) had a higher HAQ at baseline (1). Here we investigated the change in patients reported outcomes (PRO) over time in ACPA+ at risk of IA subjects.

Objectives: In ACPA+ subjects at risk of developing IA, to analyse the change in PRO results in order to identify an imminent phase of progression.

Methods: In a single centre prospective observational cohort, PRO from 109 ACPA+ subjects without clinical arthritis were collected prospectively at 0,12 , 26, 39 weeks; the last time-point was 52 weeks for the individuals who did not progress to IA (non-progressors) or the last visit preceding progression (within 12 weeks) for those who developed IA (progressors). Data on the following PRO were collected: HAQ, "general health" (GH-VAS), "fatigue" (fatigue-VAS), and "global pain" (GP-VAS) using visual analogic scale measures graded 0 to 100. We firstly used mixed models repeated measures ANOVA analysis then included covariates such as gender, shared epitope (SE) (HLA DRB1*01, ${ }^{*} 04$ and/or *10), anti-CCP2 antibody (CCP2) and/or rheumatoid factor (RF) high titre ( $\geq 3 \mathrm{ULN}$ ), and smoking exposure (Ever/Never).

Results: All analysis met sphericity assumption. In this selection, $20 \%$ of subjects (24/109) developed IA within a median of 77 weeks (Range 37-369.43), non-progressors were followed for a median of 216 weeks (Range 50-590), 74 subjects were SE positive (68\%), 81 had a CCP2 and/or RF high titre (74\%), and 66 were previous or current smokers $(61 \%)$.

Analysis revealed significant differences between both groups for the last visit, and within the progressor group for the last visit compared to all previous visits regarding the GH-VAS, GP-VAS and HAQ (Table 1, figure 1). Between subject analysis showed a significant influence of GH-VAS and GP-VAS change on progression. Covariate analysis showed a significant influence of previous smoking history on HAQ results $(\mathrm{p}=0.033, \mathrm{~F}=2.645(4,408)$, $\mathrm{Eta}=0.025)$.

Conclusion: These results show for the first time a significant deterioration in the PRO of general health, global pain, and HAQ weeks just preceding clinical arthritis development. This phase prior progression needs to be thoroughly studied to improve the accuracy of predicting imminent progression.

References:

[1] Ten Brinck RM et al. Functional limitations in the phase of clinically suspect arthralgia are as serious as in early clinical arthritis; a longitudinal study. RMD open. 2017;3(1):e000419.

Disclosure of Interests: Laurence Duquenne: None declared, Kulveer Mankia: None declared, Leticia Garcia-Montoya: None declared, Jacqueline Nam: None declared, Andrea Di Matteo Grant/research support from: the publication was conducted while Dr. Di Matteo was an ARTICULUM fellow, Paul Emery Grant/

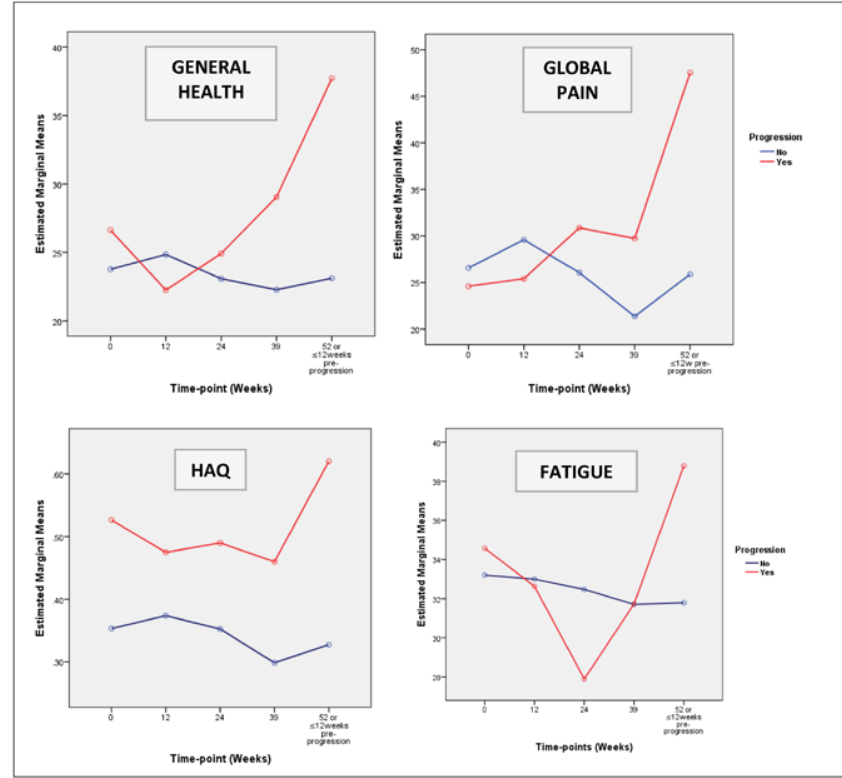

Figure 1. Repeated measure ANOVA between groups

research support from: AbbVie, Bristol-Myers Squibb, Merck Sharp \& Dohme Pfizer, Roche (all paid to employer), Consultant of: AbbVie (consultant, clinical trials, advisor), Bristol-Myers Squibb (consultant, clinical trials, advisor) Lilly (clinical trials, advisor), Merck Sharp \& Dohme (consultant, clinical trials, advisor), Novartis (consultant, clinical trials, advisor), Pfizer (consultant, clinical trials, advisor), Roche (consultant, clinical trials, advisor), Samsung (clinical trials, advisor), Sandoz (clinical trials, advisor), UCB (consultant, clinical trials, advisor)

DOI: 10.1136/annrheumdis-2020-eular.2427

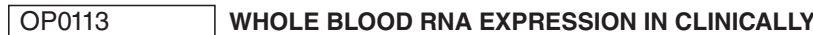 SUSPECTED ARTHRALGIA PATIENTS SHOWS A POTENTIAL ADDED VALUE IN PREDICTION OF INFLAMMATORY ARTHRITIS}

E. Niemantsverdriet ${ }^{1}$, E. Van den Akker $^{2,3}$, S. Van den Eeden ${ }^{4}$, A. Geluk ${ }^{4}$, A. Van der Helm-van Mil' ${ }^{1}{ }^{1}$ Leiden University Medical Center (LUMC), Department of Rheumatology, Leiden, Netherlands; ${ }^{2}$ Leiden University Medical Center (LUMC), Department of Biomedical Data Sciences, Leiden, Netherlands; ${ }^{3}$ Delft University of Technology (TU Delft), Pattern Recognition \& Bioinformatics, Delft, Netherlands; ${ }^{4}$ Leiden University Medical Center (LUMC),

Table 1. Mixed Models repeated measures

\begin{tabular}{|c|c|c|c|c|}
\hline & General Health & Global Pain & $\mathrm{HAQ}$ & Fatigue \\
\hline Within subject effects; & $P=0.004$ & $P<0.001$ & $P=0.115$ & $P=0.459$ \\
\hline VAS change over time depending on group. & $F(4,428)=3.883$ & $\begin{array}{l}F(4,400)=5.754 \\
\text { Partial }\end{array}$ & & \\
\hline \multirow[t]{13}{*}{ Pairwise comparison within group } & Non-progressors: & Non-progressors: & Non-progressors: & Non-progressors: \\
\hline & Progressors: & $\begin{array}{l}\text { all } \mathrm{p}>0.05 \\
\text { Progressors: }\end{array}$ & $\begin{array}{l}\text { all } p>0.05 \\
\text { Progressors: }\end{array}$ & $\begin{array}{l}\text { all } p>0.05 \\
\text { Progressors: }\end{array}$ \\
\hline & $\begin{array}{l}\text { Time-point } 1 \text { to } 5 \text { : } \\
\mathbf{p}=\mathbf{0 . 0 1 0}\end{array}$ & $\begin{array}{l}\text { Time-point } 1 \text { to } 5 \text { : } \\
\mathbf{p}<\mathbf{0 . 0 0 1}\end{array}$ & $\begin{array}{l}\text { Time-point } 1 \text { to } 5 \text { : } \\
p=0.215\end{array}$ & $\begin{array}{l}\text { Time-point } 1 \text { to } 5: \\
p=0.448\end{array}$ \\
\hline & $\mathrm{SE}=4.199$ & $\mathrm{SE}=6.172$ & Time-point 2 to 5 : & Time-point 2 to 5 : \\
\hline & Time-point 2 to 5 : & Time-point 2 to 5 : & $P=0.036$ & $P=0.292$ \\
\hline & $p=0.001$ & $\mathrm{p}<0.001$ & $S E=0.068$ & Time-point 3 to 5 : \\
\hline & $\mathrm{SE}=4.709$ & $\mathrm{SE}=5.518$ & Time-point 3 to 5 : & $P=0.047$ \\
\hline & Time-point 3 to 5 : & Time-point 3 to 5 : & $P=0.040$ & $\mathrm{SE}=5.421$ \\
\hline & $P=0.001$ & $P=0.002$ & $S E=0.062$ & Time-point 4 to 5 : \\
\hline & $\mathrm{SE}=3.842$ & $\mathrm{SE}=5.246$ & Time-point 4 to 5 : & $P=0.202$ \\
\hline & Time-point 4 to 5 : & Time-point 4 to 5 : & $P=0.017$ & \\
\hline & $P=0.043$ & $P=0.001$ & $\mathrm{SE}=0.066$ & \\
\hline & $\mathrm{SE}=4.239$ & $\mathrm{SE}=5.333$ & & \\
\hline \multirow[t]{5}{*}{ Pairwise comparison between group } & Last visit: & Last visit: & Last visit: & $P$-value $>0.05$ \\
\hline & $P=0.009$ & $P=0.003$ & $P=0.016$ & \\
\hline & $\mathrm{SE}=5.454$ & $\mathrm{SE}=7.082$ & $\mathrm{SE}=0.119$ & \\
\hline & All other visits: & All other visits: & All other visits: & \\
\hline & $P>0.05$ & $P>0.05$ & $P>0.05$ & \\
\hline Mauchly's test of sphericity & $P=0.099$ & $P=0.050$ & $P=0.057$ & $P=0.722$ \\
\hline N (Progressors/total) & $24 / 109$ & $15 / 102$ & $24 / 107$ & 19/102 \\
\hline
\end{tabular}


Department of Infectious Diseases/Immunohematology and Blood Transfusion, Leiden, Netherlands

Background: Clinically suspect arthralgia (CSA) can precede development of clinically evident inflammatory arthritis (IA). Autoantibody, C-reactive protein $(\mathrm{CRP})$, and subclinical inflammation are known predictors, but risk estimation remains insufficiently accurate. Especially CRP has a small effect size and is inadequately reflective of inflammation that can be measured systemically. RNA expression in whole blood of patients with rheumatoid arthritis (RA) have shown differences compared to healthy individuals. Therefore, we hypothesized that differences in RNA expression can be found between CSA patients that do and do not progress to IA

Objectives: This study assessed whole blood RNA expression levels of inflammatory and immune genes as potential biomarkers for prediction of IA-development in patients with arthralgia.

Methods: Between April 2012-March 2015, 234 patients were consecutively included in the Leiden CSA-cohort. Follow-up ended when patients developed clinically apparent IA (determined at physical examination), or else after 2-years. RNA expression in whole blood, at the moment of inclusion, was determined for 135 genes of the innate and adaptive immune system by dual color Reverse-Transcription Multiplex Ligation-dependent Probe Amplification (dcRTMLPA) profiling. Cox proportional hazard models were used to associate timeto-event with gene expression level at inclusion, while adjusting for age, gender, and assay plate (model 1). The false discovery rate was used to correct for multiple testing. Genes with significantly different expression were subsequently studied for reproducibility by $\mathrm{qPCR}$, and mutual independence in their association with IA-development. For the latter, we employed a forward selection strategy, starting with the most significantly associated gene and iteratively adding more genes. Resulting mutually independent genes were further investigated for their added predictive value over known risk factors, CRP, ACPA, and subclinical joint inflammation.

Results: $21 \%$ of CSA-patients developed IA after mean 3.6 months (IQR:1.610.7) follow-up. After correction for multiple testing, six genes were significantly associated with IA-development (model 1), namely IFN- $\gamma$, PHEX, IGF-1, IL7R, CD19, or CCR7 (ordered by significance). For all six genes, a lower expression at inclusion was associated with an increased risk of IA-development. IFN- $\gamma$ was only weakly expressed in peripheral blood, hampering the technical reproducibility between MLPA and GPCR results, and was excluded for further analyses. PHEX and IGF-1 were highly correlated $\left(R^{2} 0.97\right)$ and only IGF-1, but not PHEX, was included in further analyses. Of the remaining significant genes (IGF-1, IL7R, CD19, CCR7), an independent association with IA-development was observed for IGF-1 and IL7R, but not for CD19 or CCR7. qPCR data of IL7R correlated with MLPA results $(p<0.001)$, confirming the robustness of the transcriptomic outcome. Lastly, when analysing IGF-1 and IL7R with known clinical predictors, both IGF-1 and IL7R remained independently associated with progression to IA. Conclusion: Six genes were differentially expressed between CSA-patients that did or did not progress to IA. Expression of IGF-1 and IL7R showed added value to regularly used predictors. Validation is warranted.

References: None.
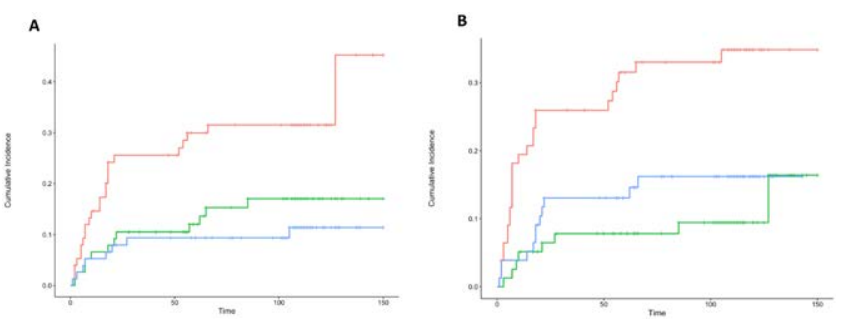

Figure 1. Association between RNA expression divided in tertiles of IGF-1 (A) and IL7R (B), and development of inflammatory arthritis

Disclosure of Interests: None declared

DOI: 10.1136/annrheumdis-2020-eular.3042

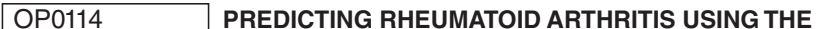 SYMPTOMS IN PERSONS AT RISK OF RHEUMATOID ARTHRITIS (SPARRA) QUESTIONNAIRE}

L. Van Boheemen ${ }^{1}$, M. Ter Wee ${ }^{2}$, M. Falahee ${ }^{3}$, M. H. Van Beers-Tas ${ }^{1}$, A. Finckh ${ }^{4}$, A. Hensvold ${ }^{5}$, K. Raza ${ }^{3}$, D. Van Schaardenburg ${ }^{1} .{ }^{1}$ Amsterdam UMC | Reade, Amsterdam, Netherlands; ${ }^{2}$ Amsterdam UMC, Rheumatology, Amsterdam, Netherlands; ${ }^{3}$ Sandwell and West Birmingham Hospitals NHS Trust, Birmingham, United Kingdom; ${ }^{4}$ University Hospital of Geneva, Geneva, Switzerland; ${ }^{5}$ Karolinska University Hospital, Stockholm, Sweden
Background: Accurate prediction of rheumatoid arthritis (RA) development in persons at risk of RA can help to select individuals for early intervention trials. Currently, RA prediction mostly relies on biomarkers such as genetic factors autoantibodies and imaging abnormalities, with symptoms being only a minor component ${ }^{1-3}$. However, at-risk individuals exhibit a high prevalence of diverse and often severe symptoms ${ }^{4,5}$ and information on the predictive ability of individual symptoms or symptom complexes is still largely lacking.

Objectives: We investigated the prevalence and predictive ability of symptoms in persons at-risk of RA, using the validated 'Symptoms in Persons At Risk of Rheumatoid Arthritis' (SPARRA) questionnaire.

Methods: Individuals at-risk of RA from four different cohorts from the Netherlands $(n=122)$, United Kingdom $(N=90)$, Sweden $(N=13)$ and Switzerland $(N=20)$ were asked to fill out the SPARRA questionnaire, consisting of 69 questions (previously described ${ }^{6}$ ). Individuals were either defined as persons with anticitrullinated protein antibodies (ACPA) and/or rheumatoid factor (RF; $n=193$ ), having relevant symptoms (i.e. clinically suspect arthralgia with or without RA-specific antibodies, $n=70$ ) or being first degree relatives (FDR, $n=20$ ) of RA patients. All were followed for a minimum of $\mathbf{2 4}$ months or until clinical arthritis development. Univariable analyses were performed for possible predictor selection $(p<0.2)$ followed by stepwise forward selection (by Cox regression, $p<0.1$ ) to create a multivariable prediction model.

Results: The mean age of all participants was 49 years and $69 \%$ was female. In total, 56 persons (23\%) developed clinical arthritis $(n=22,25,7,2$ respectively in the 4 groups) after a median of 11.9 months (IQR $5.3-17.8$ ). In total, 23 SPARRA questions were selected from the univariable analyses and entered in the stepwise forward selection procedure. Time to development of RA was predicted by the following questions: pain moving from joint to joint, having moderate or severe swelling in joints, feeling $\geq 1$ days fatigue per month and feeling stiffness in joints of one and both feet (table 1).

Table 1. Multivariable prediction model of SPARRA questions to predict clinical arthritis

\begin{tabular}{lc}
\hline & HR $(95 \% \mathrm{Cl}), \mathrm{p}$ \\
\hline $\begin{array}{l}\text { Does your joint pain move from joint to joint? } \\
\text { No; from arms to legs; from legs to arms (ref) }\end{array}$ & 1 \\
$\begin{array}{l}\text { From ons side to the other } \\
\text { Over the past month how much joint swelling have you had? }\end{array}$ & $2.96(1.57 ; 5.57), \mathrm{p}=0.001$ \\
$\begin{array}{l}\text { None or mild (ref) } \\
\text { Moderate or severe }\end{array}$ & 1 \\
$\begin{array}{l}\text { Over the past month how many days of the month have you } \\
\text { had fatigue? }\end{array}$ & $3.04(1.48 ; 6.25), \mathrm{p}=0.003$ \\
0 (ref) & 1 \\
$\geq 1$ & $0.32(0.15 ; 0.67), \mathrm{p}=0.003$ \\
Where did you feel joint stiffness? & \\
Neither feet (ref) & \\
One foot & $0.93(0.42 ; 2.08), \mathrm{p}=0.865$ \\
Both feet & $0.40(0.17 ; 0.93), \mathrm{p}=0.032$ \\
\hline
\end{tabular}

Conclusion: Asking persons at-risk of RA about joint pain, swelling and stiffness is common clinical practice. However, specific details such as pain moving from one side to the other or degree of joint swelling may provide useful additional information to estimate a person's RA risk. The protective effect noted for fatigue and stiff feet may reflect an underlying pain syndrome rather than $\mathrm{RA}$ risk. We are currently performing analyses of the potential added value of SPARRA questions over the clinical prediction model by van der Stadt et $\mathrm{al}^{3}$ which will help determine the final format of the SPARRA questionnaire.

References:

[1] de Hair MJ et al. Ann Rheum Dis. 2013;72(10):1654-8.

[2] Rakieh C et al. Ann Rheum Dis. 2015;74(9):1659-66.

[3] van de Stadt LA et al. Ann Rheum Dis. 2013;72(12):1920-6.

[4] Smolik I et al. J Rheumatol. 2013;40(6):818-24.

[5] Stack RJ et al. Arthritis Care Res (Hoboken). 2013;65(12):1916-26.

[6] van Beers-Tas MH et al. RMD Open. 2018;4(1):e000641.

Acknowledgments: Supported by EULAR

Disclosure of Interests: Laurette van Boheemen: None declared, Marieke ter Wee: None declared, M. Falahee: None declared, M.H. van Beers - Tas: None declared, Axel Finckh Grant/research support from: Pfizer: Unrestricted research grant, Eli-Lilly: Unrestricted research grant, Consultant of: Sanofi, AB2BIO, Abbvie, Pfizer, MSD, Speakers bureau: Sanofi, Pfizer, Roche, Thermo Fisher Scientific, Aase Hensvold: None declared, Karim Raza Grant/research support from: $\mathrm{KR}$ has received research funding from AbbVie and Pfizer, Consultant of: KR has received honoraria and/or consultancy fees from AbbVie, Sanofi, Lilly, Bristol-Myers Squibb, UCB, Pfizer, Janssen and Roche Chugai, Speakers bureau: $\mathrm{KR}$ has received honoraria and/or consultancy fees from AbbVie, Sanofi, Lilly, Bristol-Myers Squibb, UCB, Pfizer, Janssen and Roche Chugai, Dirkjan van Schaardenburg: None declared DOI: 10.1136/annrheumdis-2020-eular.3093 